[Agr. Biol. Chem., Vol. 27, No. 2, p. 128 132, 1963]

\title{
Cell Bound $\alpha$-Amylase in Aspergillus oryzae
}

\author{
Part III. Fixation of Exocellular $\alpha$-Amylase to Mycelia \\ By Kenzo Tonomura, Katsumichi Iwama*, Fusae Futai \\ and Osamu Tanabe \\ Fermentation Research Institute, Chiba
}

Received August 29, 1962

\begin{abstract}
It has been found that exocellular $a$-amylase could be fixed to mycelia of Aspergillus oryzae at an acidic $\mathrm{pH}$ region and fixed $a$-amylase was released reversely at an alkaline $\mathrm{pH}$ region. The fixation has more remarkably been observed in mycelia obtained from a phosphate deficient medium where endocellular accumulation of $a$-amylase occurs more easily than in an ordinary mycelia which secrete a large amount of $a$-amylase into medium. Bound form of $a$-amylase was more resistant to low $\mathrm{pH}$ and less active than the free form. The results appear to support the previous suggestion that a large quantity of endocellular $a$ amylase might be located on mycelial surface of the mold.
\end{abstract}

$a$-Amylase can always be observed in mycelia of Aspergillus oryzae as well as in the medium. It has been described in the previous papers that bound a-amylase increases when the mold is grown on phosphate deficient medium $^{1)}$ and the liberation of bound $a$-amylase into the surrounding medium is rapidly induced at an alkaline $\mathrm{pH}$ region or by an addition of phosphopeptides ${ }^{2}$. In the present paper it is described that the mycelia are capable of fixing $a$-amylase from a surrounding medium at an acidic $\mathrm{pH}$ region, and that an increase of endocellular $a$-amylase activity is not based on the synthesis during the fixation. The results obtained in this paper appear to support the previous suggestion that a large quantity of bound $a$ amylase might be located on the mycelial surface.

* Tokyo University of Agriculture and Technology.

1) K. Tonomura et al, This Journal, 26, 10 (1962).

2) K. Tonomura et al, ibid., 26, 434 (1962).

\section{METHODS}

Organism. Aspergillus oryzae, strain 557.

Culture. The mold was usually grown in the following medium (Ac) for 2 days at $30^{\circ} \mathrm{C}$ on a shaker: $29 \mathrm{~g}$ glucose; $1 \mathrm{~g}$ maltose; $2 \mathrm{~g} \mathrm{NaNO}$; $0.05 \mathrm{~g}$ $\mathrm{K}_{2} \mathrm{HPO}_{4} ; 0.5 \mathrm{~g} \mathrm{MgSO}_{4} \cdot 7 \mathrm{H}_{2} \mathrm{O} ; 0.5 \mathrm{~g} \mathrm{KCl} ; 0.01 \mathrm{~g} \mathrm{FeSO}_{4} \cdot$ $7 \mathrm{H}_{2} \mathrm{O}$; distilled water $1 \mathrm{l}$. In this medium endocellular accumulation of $a$-amylase occurred ${ }^{1)}$. The washed mycelia were used for the fixation of $a$-amylase.

The Fixation of $\alpha$-Amylase to Mycelia. The crystalline $a$-amylase was used in this study. In an earlier work the fixation was observed in aqueous solution of $a$-amylase, but later it was also observed in the solution supplemented with $\mathrm{M} / 100$ acetate buffer at pH 4.8 plus $\mathrm{M} / 1000$ calcium acetate. The mycelia were suspended at a concentration of about $40 \mathrm{mg}$ in $10 \mathrm{ml}$ of the fixation medium, and incubated at $30^{\circ} \mathrm{C}$ for 30 minutes, next removed by filtration, and washed with distilled water. $a$-Amylase activity was assayed in filtrate as well as in mycelia. An extent of the fixation was calculated from activity disappeared from medium. The endocellular activity after fixation usually recovered more than 90 per cent of the sum of the disappeared activity and the initial activity that was bound to mycelia before fixation.

The Assay of $\alpha$-Amylase Activity. The activity was 
assayed by starch iodine reaction ${ }^{1)}$. Bound $a$-amylase was assayed on a preparation obtained by grinding the mycelia in a mortar and followed by extracting twice with $10 \mathrm{ml}$ of phopshopeptides solution ${ }^{2)}(1 \mu \mathrm{M} /$ $\mathrm{ml}$, as organic phosphate) of $\mathrm{M} / 25$ phosphate buffer at $\mathrm{pH}$ 7.9.

The Preparation of Crystalline $\alpha$-Amylase Labeled with $\mathbf{S}^{35}$. Crystalline $a$-amylase was prepared from culture filtrate of the mold or from Takadiastase according to the method of $\mathrm{Akabori}^{3)}$. In the former case the mold was grown for 6 days in medium $\mathrm{Se}^{1}$, where magnesium sulfate was labeled with $S^{35}$. The specific activity of crystalline $a$-amylase was 3.5 units per count per minute.

\section{RESULTS}

\section{a-Amylase Fixation to Mycelia.}

As shown in Fig. 1 the fixation of $a$-amylase to mycelia took place very rapidly and almost independently upon the temperature, like the liberation of $a$-amylase from mycelia2). It has been proved in Fig. 2 that the fixation is strictly dependent on $\mathrm{pH}$ in the medium as in the case of liberation. When $\mathrm{pH}$ in the medium is reduced, a-amylase moves from medium to mycelia and when increased, it moves to an opposit direction. These results

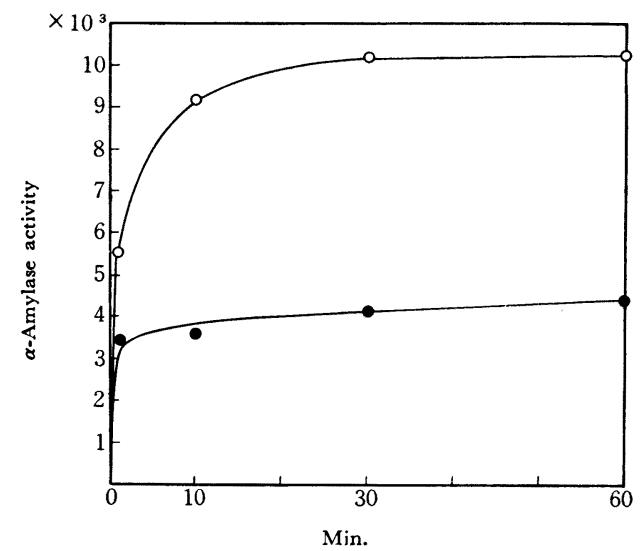

FIG. 1. Time Course of Fixation of $\alpha$-Amylase to Mycelia.

Added $\alpha$-amylase activity was $1 \times 10^{4}$ units in $\mathrm{ml}$ of the medium. $\longrightarrow, 30^{\circ} \mathrm{C} ;-0 \sim 1^{\circ} \mathrm{C}$. Methods are described in the text.

3) S. Akabori et al, J. Biochem, 41, 557 (1954).

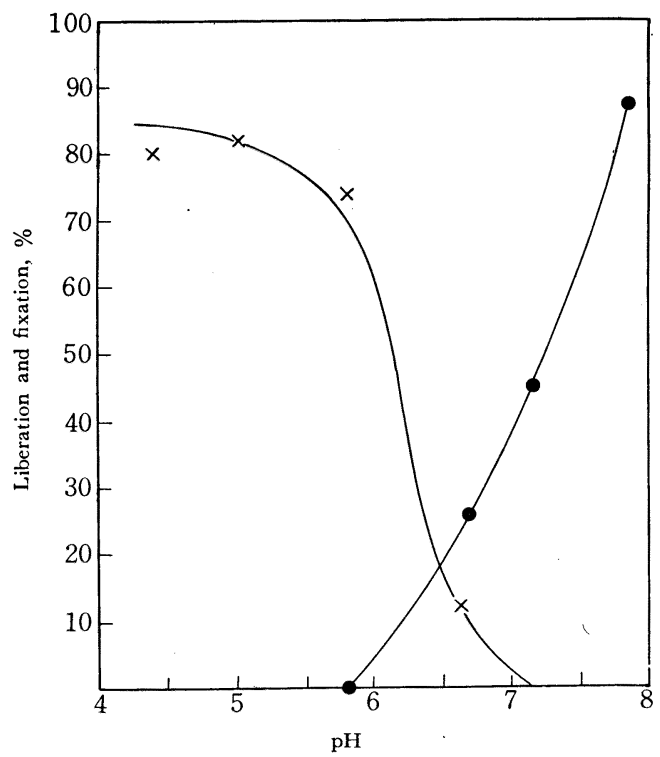

FIG. 2. Relation Between Fixation and Liberation of $\alpha$-Amylase.

For the liberation, - mycelia Ac were incubated with $\mathrm{N} / 15$ phosphate (above $\mathrm{pH} 6.7$ ) or acetate buffer (below $\mathrm{pH} 5.8$ ) . For the fixation, - $\longrightarrow$, mycelia Ac were incubated in $\mathrm{N} / 20$ acetate or phosphate buffer. $\alpha$-Amylase activity bound to mycelia prior to the fixation was 2630. Added $\alpha$-amylase activity was 3335 . See the text for detail.

appear to suggest a view that the fixation might account for the endocellular accumulation of $a$-amylase observed in the previous paper ${ }^{1)}$. The fixation has also been observed in mycelia Se, that secrete a large amount of $a$-amylase into medium, as well as in mycelia Ac. As to the maximum amount of fixed $a$-amylase, an example showed about $25 \mu \mathrm{g}$ of crystalline $a$-amylase per $\mathrm{mg}$ of dry mycelia, up to which fixed $a$-amylase increased linearly in proportion to added a-amylase, although it varies to some extent according to the conditions of mycelia used.

Interrelation Between Fixation and Liberation.

In order to compare the location and the binding form of fixed $a$-amylase with these of bound $a$-amylase existed prior to a fixation, S-labeled $a$-amylase was used. The results shown in Table $I$ indicate that fixed and 
TABLE I. LiBeration OF FIXED $\alpha$-AMYLASE

\begin{tabular}{|c|c|c|c|}
\hline \multirow[t]{2}{*}{$\alpha$-Amylase } & Activity & $\begin{array}{l}\text { Radio- } \\
\text { activity }\end{array}$ & $\begin{array}{l}\text { Specific } \\
\text { activity }\end{array}$ \\
\hline & $\mathrm{u}$ & cpm & $\mathrm{cpm} / \mathrm{u}$ \\
\hline Bound initially & 7000 & & \\
\hline Added & 5560 & 1100 & 0.20 \\
\hline Fixed & 12500 & $(1100)$ & $(0.09)$ \\
\hline Liberated at $\mathrm{pH} 6.6$ & 3570 & 620 & 0.17 \\
\hline Liberated at $\mathrm{pH} 7.8$ & 8700 & 905 & 0.10 \\
\hline
\end{tabular}

S-Labeled $\alpha$-amylase fixed to mycelia Ac was liberated in the presence of $\mathrm{m} / 100$ phosphate buffer at $\mathrm{pH} 6.6$ or 7.8 .

labeled $a$-amylase was more easily liberated from mycelia than bound and non labeled a-amylase prior to the fixation. However, it has no evidence that there is fundamentally a difference between them, because some of bound a-amylase prior to the fixation can be liberated together with fixed a-amylase. From the result it might be suggested that some sites are different in the binding activity and the fixation starts from the strongest site in order of the activity. In order to demonstrate that fixed $a$-amylase is present in mycelia without being decomposed, S-labeled $a$-amylase was fixed to mycelia and then liberated from them. The medium was concentrated and subjected to a zone electrophoresis (Fig. 3). The specific activities are compared in Table II. The results show that almost all fixed $\alpha$-amylase could be recovered again without any decomposition.

TABle II. The SPECIFIC Activity of Fixed AND LIBERATED $\alpha$-AMYLASE

$\begin{array}{lccc}\alpha \text {-Amylase } & \begin{array}{c}\text { Total } \\ \text { activity }\end{array} & \begin{array}{c}\alpha \text {-AA/ } / \mu \mathrm{g} \\ \text { of }\end{array} & \begin{array}{c}\alpha \text {-AA/ } \\ \text { cpm }\end{array} \\ \begin{array}{l}\text { und initially } \\ \text { non-labelled) }\end{array} & 1070 & & \\ \text { ded (labelled) } & 8330 & 2.9 & 3.5 \\ \text { und after fixation } & 8700 & & \\ \text { perated } & 6667 & 2.3 & 3.5 \\ \text { peak No. 12 } & & 2.6 & 3.6\end{array}$

Fixed $\alpha$-amylase was liberated by incubating mycelia with $\mathrm{M} / 50$ phosphate buffer at $\mathrm{pH}$ 7.2. Zone electrophoresis was carried out on the liberation medium obtained above.

\section{Characteristics of the Fixation.}

The fixation of $a$-amylase to mycelia was compared with the adsorption to starch. As

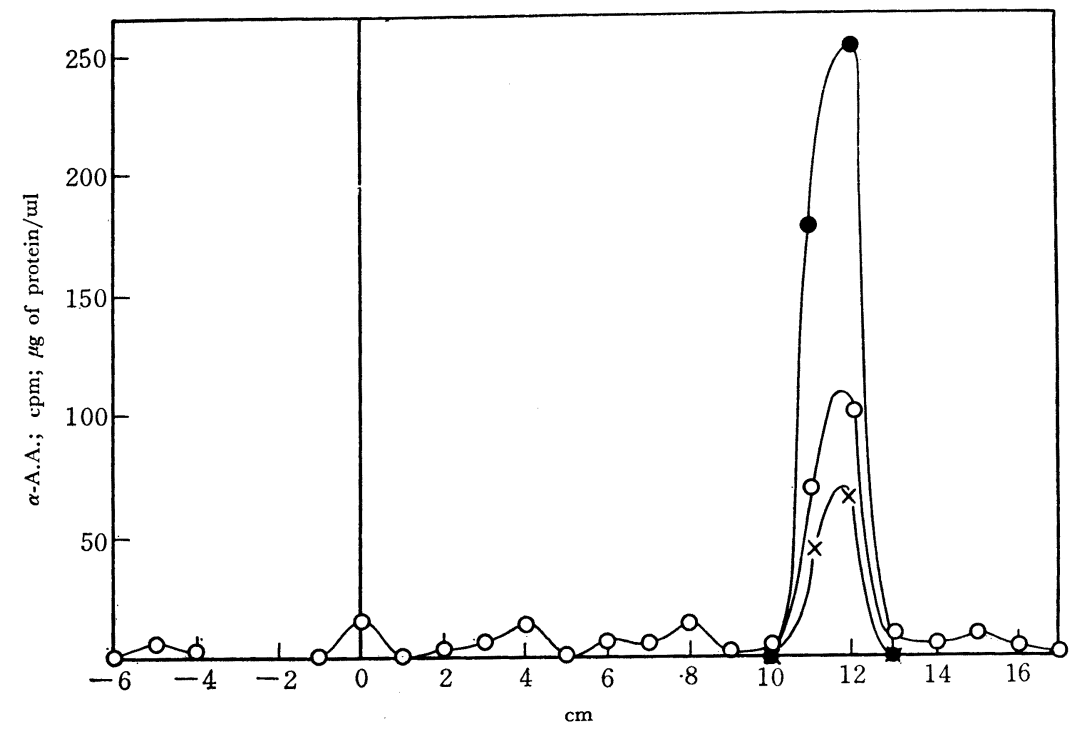

FIG. 3. Diagram of Zone Electrophoresis of $\alpha$-Amyiase Liberated from Mycelia after Fixation.

Zone electrophoresis on starch column $(35 \times 5 \times 1.5 \mathrm{~cm})$ was carried out at 260 volt, $7.2 \mathrm{~mA}$ for $16 \mathrm{hr}$ using veronal buffer at $\mathrm{pH} 8.7$, ionic strength 0.05 . After a run, starch block was cut in $1 \mathrm{~cm}$ sections and eluted with water. The eluates were determined for protein - 
TABLE III. COMPARISON OF $\alpha$-AMYLASE FIXATION BETWEEN TO MYCELIA AND TO STARCH

\begin{tabular}{lllc} 
Fixation to or & \multicolumn{2}{c}{ Fixation } & Liberation \\
liberation from & Medium & $\%$ & $\%$ \\
Mycelia & Water & 40 & 0 \\
Mycelia & $40 \%$ Ethanol & $-*$ & \\
Starch & Water & 0 & \\
Starch & $40 \%$ Ethanol & 90 & 83
\end{tabular}

Soluble starch washed with ethanol and distilled water was used for the fixation. $\alpha$-Amylase was added to mycelia Ac (40 mg dry weight) or starch $(500 \mathrm{mg})$ suspended in water or $40 \%$ ethanol $(10 \mathrm{ml})$. Fixed $\alpha$-amylase was liberated with $10 \mathrm{ml}$ of watcr. *The fixation could not apparently be observed on account of the liberation of $\alpha$-amylase from mycelia in the presence of $40 \%$ ethanol.

it has been indicated that $a$-amylase is adsorbed most efficiently on starch $^{4}$ especially in the presence of ethanol, so the adsorption was compared with the fixation to mycelia. As shown in Table III, the adsorption on starch was remarkable in the presence of 40 per cent ethanol, in contrast to the fixation that was observed even in an aqueous solution but not in 40 per cent ethanol. The striking difference was further observed in the liberation of adsorbed $a$-amylase from starch comparing with that from mycelia. a-Amylase fixed to mycelia was not easily liberated by washing with distilled water, but that adsorbed on starch was easily liberated. It is evident that the fixation to mycelia is different from the adsorption on starch.

The fixation was inhibited by using mycelia which were frozen and thawed prior to the fixation (about $46 \%$ inhibition). The inhibition was also observed in the presence of 0.01 per cent sodium lauryl sulfate (about $10 \%$ ), 40 per cent ethanol (about $100 \%$ ) and phosphopeptide in $1 \mu \mathrm{M} / \mathrm{ml}$ as organic phosphate (about $50 \%$ ), and at an alkaline $\mathrm{pH}$ of a suspension medium as described before. These are the factors which induce mycelia to the liberation.

Properties of Bound $\alpha$-Amylase.

It has been indicated by Isemura ${ }^{5)}$ that

4) S. Schwimmer and A.K. Balls, J. Biol. Chem., 180, 883 (1949) 5) T. Takagi and T. Isemura,, J. Biochem., 49, 43 (1961).

more than 20 of the 40 carboxyl groups in a Taka-amylase molecule are in a masked state as carboxylate ions and combine with hydrogen ions irreversibly below $\mathrm{pH} 4.3$, and that the acid-denaturation occurs with the unmasking of the carboxylate groups. However, results in Table IV show that $a$-amylase bound to mycelia is resistant to low $\mathrm{pH}$ below 4.5. Besides, $a$-amylase is fixed to mycelia at an acidic $\mathrm{pH}$ region as mentioned above. From these results it is evident that $a$-amylase is protected from the inactivation at low $\mathrm{pH}$ by being fixed to mycelia.

It is shown in Table $\mathrm{V}$ that mycelia bound $a$-amylase are capable of hydrolying starch just as it binds, although the hydrolysis is remarkably enhanced when mycelia are disrupted to make the enzyme free. This also appears to support our concept that a large amount of bound $\alpha$-amylase might be located on the surface of mycelia, because of

TABLE IV. AcID-RESISTANT Bound $\alpha$-AMYLASE

\begin{tabular}{|c|c|c|c|}
\hline \multirow{2}{*}{$\begin{array}{l}\text { Form of } \\
\alpha \text {-Amylase }\end{array}$} & \multicolumn{2}{|c|}{ Activity } & \multirow{2}{*}{$\begin{array}{c}\text { Inactivation } \\
\%\end{array}$} \\
\hline & $\begin{array}{c}\text { Before } \\
\text { treatment }\end{array}$ & $\begin{array}{c}\text { After } \\
\text { treatment }\end{array}$ & \\
\hline Free & 2940 & 1350 & 54 \\
\hline Bound & 2995 & 3015 & -0.7 \\
\hline
\end{tabular}

Crystalline $\alpha$-amylase was dissolved in $\mathrm{M} / 1000$ calcium acctate plus $\mathrm{m} / 100$ acetate buffer at $\mathrm{pH}$ 4.5. For the fixation mycelia were suspended and incubated in above solution at $30^{\circ} \mathrm{C}$ for 30 minutes. For treatment with acid, $M / 10$ acetic acid was added to the solution or the suspension so as to reduce $\mathrm{pH}$ to 4.27. After being kept at $30^{\circ} \mathrm{C}$ for 30 minutes, each medium was adjusted to $\mathrm{pH} 7$ with an addition of phosphate.

TABle V. COMPARATIVE ACTIVITY OF BOUND AND FREE $\alpha$-AMYLASE

$\alpha-$ Amylase

(a) Ground mycelia

(b) Intact mycelia

(c) Medium used for assay (b)

(d) Ground mycelia after assayed (b)

Mycelia Ac were divided into two parts. One was ground in a mortar and extracted as usual (a). The other was added into the reaction mixture for the assay without grinding and assayed for the activity (b). After that, the mycelia were immediately removed from the mixture and $\alpha$-amylase activity was assayed in the mixture (c) and in the mycelia (d). The assay was carried out at $30^{\circ} \mathrm{C}$. 
a view that if the enzyme is located inside the cell, it could not hydrolyze the substrate.

\section{DISCUSSION}

Although a large quantity of $a$-amylase has been found in mycelia grown on phosphate deficient medium, some of the activity can always be found in normal mycelia. As long as comparing with properties on the liberation and fixation, there seems to be no distinction between these two bindings except an intensity of the binding activity.

It has been suggested that bound $a$-amylase might be located on a mycelial surface, from the results that $a$-amylase can be bound to and liberated from mycelia reversibly, and that the substrate starch can be hydrolyzed by bound $a$-amylase itself although it is less active than free $a$-amylase.

In microbial cell surface several enzymes have been found ${ }^{6)}$, but there are few studies to indicate such a localization in fungi, though there are a few studies concerning to chemical properties of fungal cell wall. BartnickiGarcia $^{7)}$ pointed out a complex composition of cell wall of Mucor rouxii, consisting of polysaccharides, phosphates, proteins, lipids, purines and pyrimidines, $\mathrm{Mg}^{++}$and $\mathrm{Ca}^{++}$. Horikoshi $^{8)}$ reported the presence of $\beta-1,3-$ glucan as well as chitin in Aspergillus oryzae. Crook $^{9)}$ found neutral sugars, amino sugars and amino acids in fungal cell wall.

The most interesting finding has been indicated by Harold ${ }^{10}$ ) that cell wall of Neurospora crassa can bind inorganic polyphosphate through the formation of two complexes: in

\footnotetext{
6) M.R. J. Salton, Bact. Rev., 25, 77 (1961).

7) S. Bartnicki-Garcia and W.J. Nickerson, Biochim. Biophys. Acta., 58, 102 (1962).

8) K. Horikoshi, ibid., 57, 392 (1962); Symp. of Inst. of Applied Microbiology, Tokyo Univ. (1961).

9) E.M. Crook and I.R. Johnston, Biochem. J., 83, 325 (1962).

10) F.M. Harold, Biochim. Biophys. Acta., 57, 59 (1962).
}

an acid environment, an acid-dissociable complex was formed due to interaction of the polyphosphate with protein components of the cell wall; a second complex, stable to cold acid, resulted from interaction of the polyphosphate with free amino group of polygalactosamine.

Considering a complexity of fungal cell wall, the authors conclude that a-amylase could be bound to a certain substance on cell surface. Our study is now in progress concerning to binding of $a$-amylase to amino groups in the cell wall fraction.

\section{SUMMARY}

1. It was found that $a$-amylase, exocellular enzyme, was fixed to mycelia of Aspergillus oryzae at an acidic $\mathrm{pH}$ region. The fixation took place rapidly and almost independently upon a temperature.

2. The fixed a-amylase was liberated from mycelia at an alkaline $\mathrm{pH}$ region. The liberation of fixed a-amylase occurred more easily than a-amylase which was bound to mycelia prior to the fixation. However, there seems to be no basic distinctions of bindings between them.

3. The fixation of a-amylase to mycelia was different from the adsorption on starch. Bound $a$-amylase was more resistant to acidinactivation, and less active than the free form.

4. These results appear to support a previous concept that a large amount of bound $a$-amylase might be located on mycelial surface in the mold.

Acknowledgement. We wish tơ express appreciation for helpful discussions and suggestions to Prof. K. Kitahara, Institute of Applied Microbiology University of Tokyo. 